\title{
THE SPATIAL DISTRIBUTION OF SEVERE CONVECTIVE STORMS AND AN ANALYSIS OF THEIR SECULAR CHANGES
}

\author{
Harold E. Brooks ${ }^{1}$ and Nikolai Dotzek ${ }^{2}$ \\ ${ }^{1}$ NOAA/National Severe Storms Laboratory, National Weather Center, 120 David \\ L. Boren Blvd., Norman, Oklahoma 73072, U.S.A. \\ ${ }^{2}$ DLR-Institut für Physik der Atmosphäre, Oberpfaffenhofen, 82234 Wessling, \\ Germany
}

\begin{abstract}
Severe convective storms are responsible for billions of US dollars in damage each year around the world. They form an important part of the climate system by redistributing heat, moisture, and trace gases, as well as producing large quantities of precipitation.

Reporting of severe convection varies from country to country, however, so that determining their distribution from the reports alone is difficult, at best. Evidence does exist that the intensity of some events, particularly tornadoes, follows similar distributions in different locations, making it possible to build statistical models of occurrence. Remotely-sensed observations provide some insight, but the relationship between the observable parameters and the actual events of interest limits the quality of the estimate. Another approach is to use observations of the larger-scale environments.

As stated, the relationship between the observation and the event limits the estimate, but global coverage is possible. Time series of the favorable environments can also be developed from such data. In order to improve the estimates, the most pressing need is better observational data of events. Very few countries have formal systems for collection of severe thunderstorm reports. A new effort from a consortium of researchers in Europe to develop a continental-wide database offers the possibility of a significant improvement in data in that part of the world.
\end{abstract}




\section{INTRODUCTION}

Convective storms play a vital role in weather and climate. They act to redistribute heat, moisture, and trace gases in the vertical and horizontal. In the tropics and in the warm season in mid-latitudes, they provide a significant part of the precipitation. As such, they are beneficial to society, particularly in agriculture. When convection is particularly strong, however, the resulting weather can have adverse effects on life and property and is typically referred to as severe. Although definitions of what is called severe vary from place to place, in general, hail, high winds, tornadoes, and extremely heavy precipitation leading to flash flooding frequently are considered. Doswell (2001) provides an overview of the problem of severe convection.

Thunderstorms occur all over the world ${ }^{1}$. Estimates of global occurrence and losses from them are not available, in general, although there are regional estimates. A recent expert survey of tornado occurrence per year in Europe, produced on a country-bycountry basis, yielded an estimate of 300 tornadoes on land and an additional 400 waterspouts (tornadoes over water) (Dotzek 2003). Munich Re estimates yearly overall losses of about 5-8 billion EUR due to severe convective storms in Europe. Approximately 1200 tornadoes are reported in the United States each year, with roughly 50 deaths and US\$400 million in damage annually with US\$10 billion for hail, based on US National Weather Service data. It is important to

1 To be precise, thunderstorms imply the existence of lightning. Maddox et al. (1997) presented evidence for inadvertent modification of thunderstorms that limits lightning. Presumably, it is possible for natural processes to accomplish the same thing. In this paper, "thunderstorm" will be used to imply deep, moist convection, the process of the rapid vertical ascent of potentially buoyant air and subsequent precipitation, cooling and moistening the planetary boundary layer and stabilizing the atmosphere, but nonthundering convection is not excluded (Doswell et al. 1996.) 
note that there is wide interannual variability in those figures. The 3 May 1999 tornado that struck Oklahoma City and the surrounding area caused US\$1 billion in damage by itself. Brooks and Doswell (2001a) estimated that, adjusting for temporal changes in economic variables, the United States can expect a billion dollars in damage from a single tornado about once per decade.

Estimates of occurrences of hail, convective wind, and convectivelyinduced flooding rainfall are much more difficult to obtain. In the United States, there are currently over 10,000 reports per year each of hail and wind. This number has increased by an order of magnitude in the last few decades, as a result of efforts to improve data collection. Attempting to know the true distribution is obviously difficult in a situation with such large temporal changes.

In this chapter, we will review the problems associated with severe convection reporting and cover a range of approaches to making estimates. Although public reports provide a straightforward way to make such an estimate, the problems with these reports (discussed in Sec. 2) make those estimates dubious at best, with the possible exception of a few regions. Eligible approaches to solving the problem, including the use of proxy observations and relationships between the environments and events of interest will be described. Finally, we will close with a discussion of possible alterations in severe thunderstorms associated with climate change and suggestions for improving data collection to address the situation.

\section{UNDERLYING PROBLEMS AND APPROACHES}

Part of the problem in defining severe convection is the susceptibility of different parts of society from the same weather event. For example, a large amount of small hail (less than $2 \mathrm{~cm}$ in diameter) may have little impact on urban areas, but could be devastating to agricultural interests at certain times of the year and for certain crops. Similarly, strong winds may have minimal impact in an area of grassland used for cattle ranching, while the same winds may be damaging in a forested or urban setting. As a result, the definitions developed in different locations are necessarily arbitrary. 
A further complication is that most severe thunderstorm events require the presence of an observer at the time and place of the event. Unlike temperature or precipitation, for example, where routine observations can be collected on a regular basis by humans or by automated systems, the intermittent, isolated nature of severe thunderstorms in time and space, and the difficulty of remotely observing the events of interest means that we depend on a fortuitous combination of the occurrence of an event and the presence of an observer to detect the event (and classify it correctly). Assuming that the event is observed is insufficient to insure that a record is made of it. In many countries there is no systematic official process to collect reports of events that are observed ${ }^{2}$. In the absence of officially-supported systems, it is difficult to create historical records of past events.

Even in the United States, which has had an official collection effort since the 1950s, there are still obvious reporting problems. Verbout et al. (2006) show that the number of tornado reports increased by approximately 14 per year from 1954 to 2004 (Fig. 8.1). Brooks and Doswell (2001b) showed that this increase comes from the increasing number of reported weak tornadoes over time, likely a result of factors such as improved public awareness, report collection procedures, increasing urbanization, or better radar identification of severe (and potentially tornadic) storms by the WSR-88D network. Further complicating the analysis is the apparent step function decrease in the number of strong and violent tornadoes that took place in the mid1970s, presumably associated with adoption of the Fujita scale ${ }^{3}$ (Fujita 1971), linking peak wind speed $v$ and scale class $\mathrm{F}$

2 We note that records exist in many countries, but that, in general, those are developed by interested individuals independent of any professional meteorological or climatological responsibilities they may have.

3 Tornadoes are rated by the maximum damage anywhere along the path. The scale goes from F0 (the weakest) to F5 (the strongest). Following Kelly et al. (1978), F0 and F1 tornadoes are referred to as "weak," F2 and F3 as "strong," and F4 and F5 as "violent.” F2 and stronger tornadoes are collectively described as "significant." 


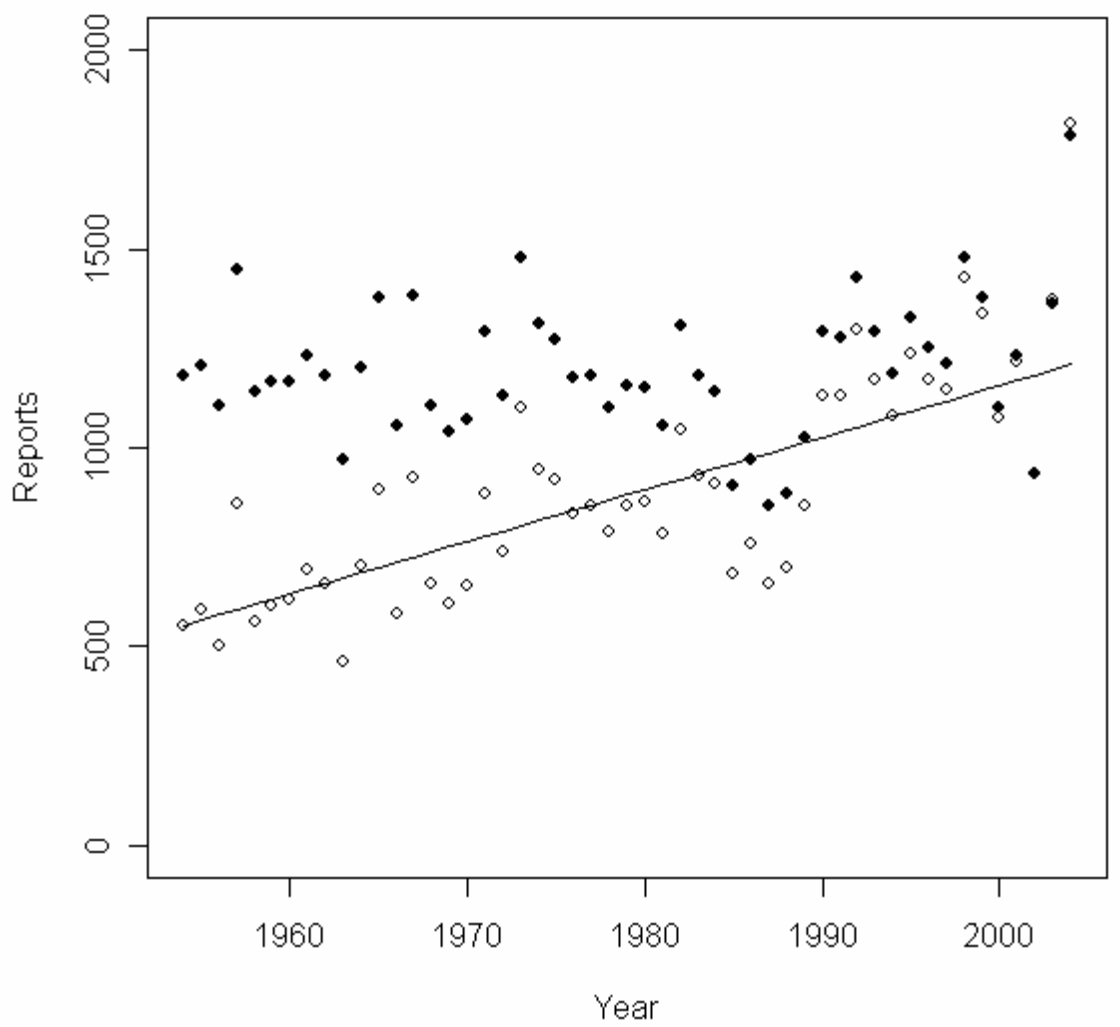

Figure 8.1. Tornado reports in official database in USA from 19542004. Raw reports (open circles), solid line (linear regression), reports adjusted to 2002 reporting system (solid circles).

$$
v(\mathrm{~F})=6.30 \mathrm{~m} \mathrm{~s}^{-1}(\mathrm{~F}+2)^{3 / 2},
$$

as a measure of tornado damage and the subsequent retrospective rating of tornadoes in the National Weather Service's database extending back to 1950 . Thus, it seems that the reasonably reliable record of tornado occurrence is perhaps 30 years or less, depending on the variable considered. 
The non-tornadic severe weather reporting problem is even more serious. Spatial and temporal changes in reports in the US make it difficult to interpret the database. Trapp et al. (2006) examined individual events during the course of a field project and found that reports of convective wind gusts in the database frequently gave a misleading impression of the scope of the event. In some cases, the reports greatly underestimated the extent of damage, compared to aerial surveys, while in other cases, the reports made relatively minor events seem more widespread, particularly in urban areas. Doswell et al. (2005) showed that differences in practice between different local National Weather Service Forecast Offices lead to discontinuities in the spatial patterns of hail and wind reports. Temporally, nontornadic reports have increased exponentially over the last 50 years from perhaps 2,000 per year in the 1950s to almost 30,000 per year now. Obviously, even a relatively large physical change of a few percent per year could be masked by such large changes in the reports.

In order to deal with some of the problems with the raw reports, Brooks et al. (2003a) and Doswell et al. (2005) put the reports onto a regularly-spaced grid, considered the variable of interest to be whether or not at least one event occurred in a 24-hour period in a particular grid box and then applied spatial and temporal smoothers to produce a continuous distribution of daily climatological probability of events. This produces fields that appear physically reasonable, but because of the smoothing, detail is obviously lost. It seems plausible that the detail is on a scale on which little confidence can be placed, given the problems in the data, but if physically-real differences occur on small spatial scales, those details will be lost. In addition, the methodology requires the existence of a relatively large database in order to produce the raw input fields. To date, such a database only exists in the USA. It is possible that the European Severe Weather Database ESWD (eswd.eu, Fig. 8.2) currently under development may produce a sufficiently high-quality database in order to carry out smoothing but that has not occurred as of yet. 

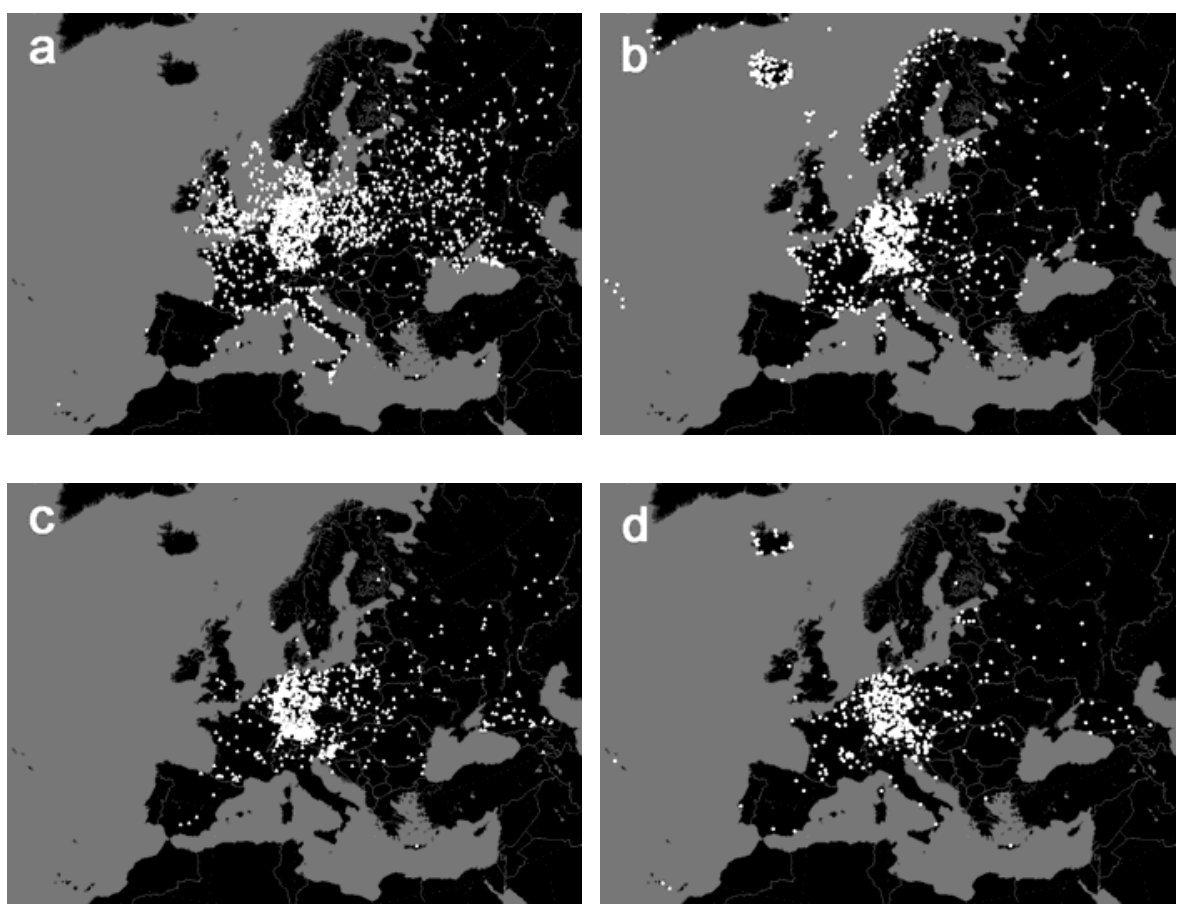

Figure 8.2. ESWD data since 1950 (as of 5 August 2006): tornadoes (a, $n=2064)$, straight-line winds (b, $n=1444)$, large hail (c, $n=988)$, and heavy rain $(d, n=598)$. Due to inclusion of the TorDACH reports, data density is presently highest in Germany.

The inherent problems with the databases from different countries do not prevent data analysis, if done carefully and cautiously. Brooks and Doswell (2001b) noted that the distribution of tornadoes by intensity appeared similar in many countries, implying that there might be an underlying physical process (or set of processes) that leads to the intensity of a tornado. Since that time, Dotzek et al. (2003, 2005) and Feuerstein et al. (2005) have worked to put that speculation on a firmer statistical footing. Dotzek et al. (2003) and Feuerstein et al. (2005) showed that Weibull distributions could be fit to the data from a variety of countries worldwide and applied a two-parameter leastsquare fit to observed worldwide tornado intensity distributions both in F-scale and wind speed $v$. With $x$ denoting either of these, the Weibull distribution is given in three-parameter form for probability density $p(x)$ : 


$$
p(x)=\frac{c}{b}\left(\frac{x-a}{b}\right)^{c-1} \exp \left(-\left(\frac{x-a}{b}\right)^{c}\right)
$$

Here, $a$ is a fixed parameter and denotes the lower boundary of the variable $x$. The scaling factor $b$ and the shape parameter $c$ are the two model parameters to be estimated. Note that for $c=1$, Eq. (2) includes the exponential distribution discussed by Brooks and Doswell (2001b), whereas $c=2$ yields the Rayleigh distribution:

$$
p(x)=\frac{2(x-a)}{b^{2}} \exp \left(-\frac{(x-a)^{2}}{b^{2}}\right) .
$$

Using the wind speed $v$ as the independent variable, i.e. substituting $v \equiv x-a$, and $v_{0} \equiv b$, Dotzek et al. (2005) were able to corroborate and generalize results by Kurgansky (2000) who had analytically predicted a Rayleigh distribution for tornado intensity distributions over wind speed. Comparing the evolution of parameter $c$ from general Weibull distribution fits worldwide, Dotzek et al. (2005) showed that for increasing quality and sample size of tornado intensity datasets, a trend towards $c=2$ can indeed be concluded.

Further support for the relevance of the Rayleigh distribution for tornado intensities comes from earlier statistical modeling work in the field of wind energy assessment. There, it has been shown that any wind speeds should be Rayleigh-distributed if $v$ can be regarded as the absolute value of a two-dimensional vector, the coordinates of which are independent and which follow a Gaussian distribution with zero mean and variance $v_{0}{ }^{2} / 2$ (cf. Conradsen et al., 1984). These conditions are best met in isotropic conditions, when no wind direction is preferred. Clearly, winds in tornado vortices fulfill these conditions even better than ordinary winds, due to their high degree of axial symmetry. 
Figure 8.3 shows the results obtained by Dotzek et al. (2005) for the observed decadal tornado intensity distributions in the USA from 1920 to 1999. To detect the presence of a Rayleigh distribution, it is helpful to exploit the fact that a Rayleigh distribution in $v$ is equivalent to an exponential distribution in $v^{2}$ (cf. Dotzek et al., 2005). Thus, Fig. 8.3a depicts the tornado intensity distributions over $v^{2}$. For all decades, clear exponential tails from F2 intensity on can be seen; from about the 1960s on, the Rayleigh distribution is already reproduced from F1 intensity on. Validity of a Rayleigh distribution is a consistent feature over the 80 years of data, even with the increasing number of reported weak tornadoes over time and the reporting issues discussed by Verbout et al. (2006).
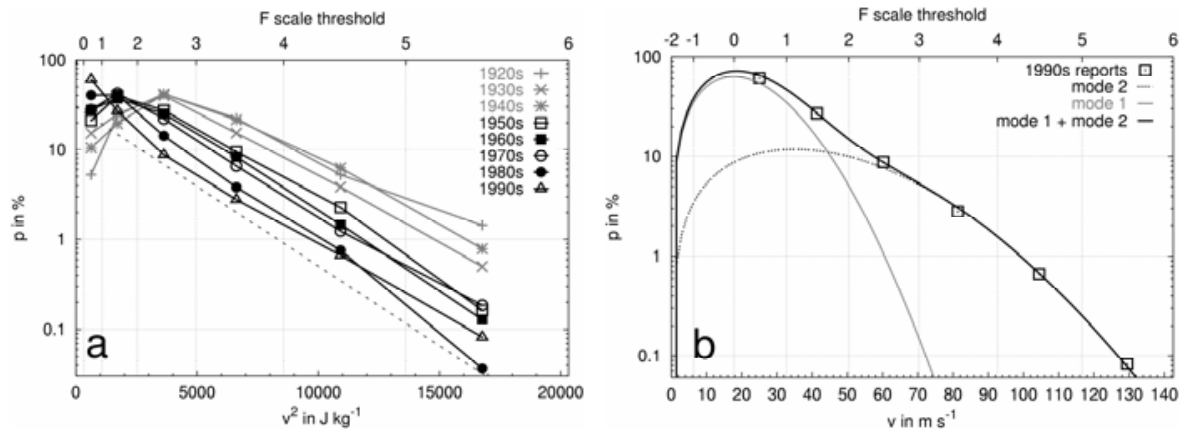

Figure 8.3. Decadal tornado intensity distributions from the USA, 1920-1999 over $v^{2}(\mathrm{a})$, and the USA 1990s data over $v(\mathrm{~b})$, showing signs of emerging bimodality into separate low- and high-intensity Rayleigh modes (solid grey and dotted, respectively). The solid black line gives the sum of both modes, and the open boxes are the observations. F-scale threshold wind speeds are also given on the upper abscissa of both panels.

The 1990s data have separately been plotted over $v$ in Fig. 8.3b. Here, a new feature appears to emerge due to enhanced detection efficiency for weak tornadoes: Bimodality. The data are now best reproduced by a superposition of two independent Rayleigh distribution modes, characterized by different variances $v_{0}^{2}$. A similar result follows from the 1990s Oklahoma data alone. The separation of the modes occurs at 
about the F2 intensity threshold $\left(50.4 \mathrm{~m} \mathrm{~s}^{-1}\right)$. The modes can be attributed with good confidence to non-mesocyclonic and mesocyclonic tornado activity, respectively (Dotzek et al., 2005).

The tornado reports in the USA from 2000 to 2005 show an even higher percentage of weak tornadoes than the 1990s, and they lack any F5 events. The latter fact may not only have meteorological reasons, but also be influenced by current tornado rating practice in the USA. Hence, even for large tornado databases probably approaching completeness in annual numbers, reporting issues remain as a limiting factor on risk assessment based on intensity distribution modeling.

One possible approach to solving the problem of report limitations is to develop proxies for the events from things that are regularly observed. Toracinta and Zipser (2000) looked at satellite-observed mesoscale convective systems in the tropics and subtropics using microwave imagery and lightning detection. Levizzani and Setvak (1996) found satellite-based signatures associated with supercell thunderstorms in the US from multi-spectral data. These approaches show promise, but currently are either limited in spatial extent or are labor-intensive. In addition, it is clear that they identify strong updrafts, which are logically related to severe thunderstorms, but it is possible, if not likely, that they do not cover the complete range of severe thunderstorms. In particular, the relationship between the observed variables and tornadoes, if there is one, is not obvious.

Bissolli et al. (2006) combined a synoptic weather pattern analysis for Central Europe in comparison with the German TorDACH tornado reports ${ }^{4}$ in the period 1950-2003. The synoptic pattern scheme by Deutscher Wetterdienst (DWD, the German national weather service) takes into account the direction of air mass advection, the cyclonicity and the humidity (precipitable water) of the troposphere. The majority of the tornadoes can be attributed to only three specific weather types,

\footnotetext{
4 http://tordach.org/de/. From 2006 on, severe weather reports from Germany only add to the ESWD, and the TorDACH reports until 2005 are converted to ESWD format and added to it.
} 
all with a southwesterly advection and high humidity. This feature is found for weak as well as for significant tornadoes. Anti-/Cyclonicity at $950 \mathrm{hPa}$ reduces/enhances the tornado frequency roughly by a factor of 2, while in $500 \mathrm{hPa}$ cyclonicity showed no significant influence. Therefore, a synoptic weather type prediction may both provide early warning guidance in operational forecasting, and become a tool in regional climate modeling, when changes in the frequency or location of synoptic patterns are to be studied for future climate scenarios.

Another proxy source of data is environmental observations. Brown and Murphy (1996) explored the use of well-observed atmospheric variables in order to deduce the presence of a poorly observed forecast variable, aircraft icing. The icing forecast problem bears some similarity to the severe thunderstorm forecast problem in that the observed event of interest depends on the presence of an observer and, in many cases, the issuance of a forecast leads to observers avoiding the region. By the use of proxy variables, the problem becomes one of establishing the relationship between the observed variable and the event of interest and then comparing the forecast to the well-observed variable. The quality of the relationship between the variable and the event puts a limit on the applicability of the technique. A workshop report from the IPCC (2002) recommended analysis of changes in favorable environments in order to look at climate change questions.

There is a long history of attempts to develop relationships between large-scale environmental conditions and severe thunderstorms and tornadoes (e.g., Beebe 1955, 1958; Brooks et al. 1994; Rasmussen and Blanchard 1998). The primary motivation for these studies has been to improve forecasting. Favorable environments for severe convection have been identified. An important result is that the discrimination between severe events and non-events is best when only the strongest severe thunderstorms are considered (e.g., F2 or stronger tornadoes, 5 $\mathrm{cm}$ or larger diameter hail, wind gusts of at least $120 \mathrm{~km} / \mathrm{h}$ ). It appears relatively easy for the atmosphere to produce thunderstorms that make marginally severe weather, but that only a limited set of conditions can lead to the most severe events. Unfortunately for this analysis, the conditions do not always produce severe thunderstorms. This stems 
from a variety of causes, perhaps most importantly, the problem of convective initiation. The over-forecasting that results from just considering the large-scale environment can be thought of as a byproduct of forecasting a rare event with high costs associated with missed detections (Brooks 2004). The identification of environments that are favorable for severe thunderstorms is likely, however, to provide a best first guess for the distribution of severe thunderstorms. In this context, convective initiation and other problems can be thought of as noise or quasi-random processes.

\section{ENVIRONMENTAL CONDITIONS ASSOCIATED WITH SEVERE THUNDERSTORMS}

A number of recent studies have highlighted convective available potential energy (CAPE) and some measure of deep tropospheric wind shear of the horizontal environmental winds (deep shear) as important discriminators between environments associated with significant severe thunderstorms and those that are not (e.g., Rasmussen and Blanchard 1998; Craven and Brooks 2004). This can be seen in the estimated probability of significant severe thunderstorm occurrence given a combination of CAPE and deep shear, based on data from the operational US radiosonde network when soundings happened to be launched in the vicinity of severe thunderstorms (so-called proximity soundings), described in Brooks and Craven (2002) and Craven and Brooks (2004) (Fig. 8.4). As the environments move towards greater CAPE and deep shear, the probability of the environment being associated with a significant severe storm increases rapidly. To first order, the gradient in probability is perpendicular to the product of the CAPE and deep shear.

The principal parameters that discriminate between significant tornadic and significant non-tornadic environments are the height of the lifted condensation level (LCL) and measures of lower tropospheric wind shear (Rasmussen and Blanchard 1998; Craven and Brooks 2004). Tornadic environments are favored when the LCL height is low and the wind shear in the lowest kilometer above the ground is high. 


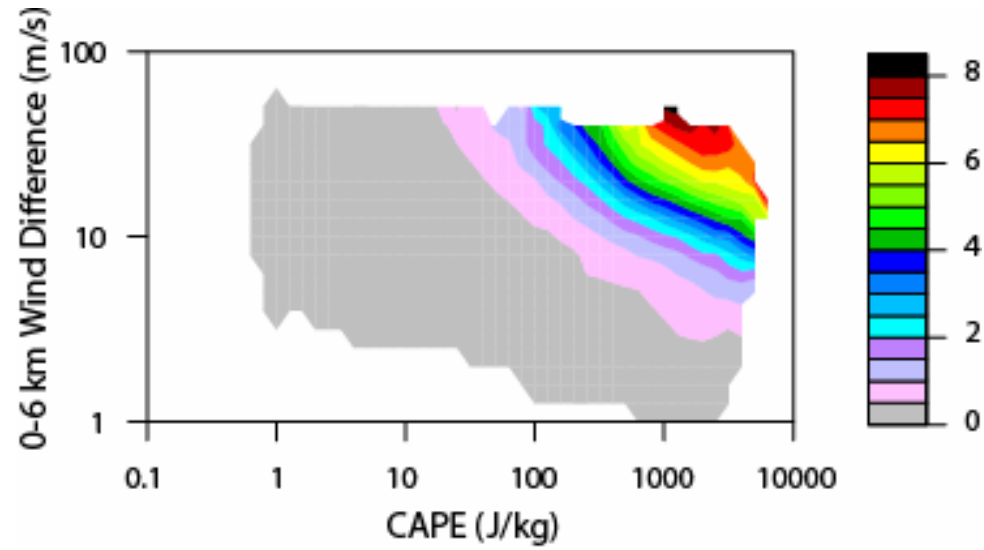

Figure 8.4. Probability in percent of environment producing severe thunderstorm with a tornado with at least F2 damage, $5 \mathrm{~cm}$ diameter hail, or $120 \mathrm{~km} \mathrm{~h}^{-1}$ wind gusts. Based on data described by Brooks and Craven (2002).

These two steps in discrimination (severe vs. non-severe, tornadic vs. non-tornadic) can form the basis of identifying environments that are favorable for various classes of weather events. Given the sparse coverage of upper-air observations, however, carrying the discrimination to other locations is challenging. To address this problem, Brooks et al. (2003b) attempted to use data from the National Center for Atmospheric Research/National Centers for Environmental Prediction global reanalysis dataset. The reanalysis was treated as a source of pseudo-proximity soundings and the analysis of Brooks and Craven (2002) was repeated (Lee 2002).

Discrimination between the severe and non-severe environments was found to be almost identical to the observed dataset. Discrimination was not as good, but still used the same variables in the same qualitative sense. Problems with sharp vertical gradients and the boundary layer in the reanalysis are likely sources of the differences.

Brooks et al. (2003b) counted the number of days per year with conditions that the reanalysis identified as favorable for significant severe thunderstorms and tornadoes from a seven-year period over the 
land area of the globe. Here, we present updated versions of those figures, counting the number of individual six-hour time slices per year from 1970-1999 (Fig. 8.5). Severe thunderstorms are concentrated downstream of high terrain and poleward of moisture sources in the form of warm water or rainforest. This is because of the high mid-tropospheric lapse rates that advect off the high terrain over the boundary layer moisture, creating a high-CAPE environment when the flow aloft is from the direction of the high terrain and the flow at low levels is poleward. The change of the wind direction with height associated with this configuration implies the presence of significant vertical wind shear, the second important parameter for severe thunderstorms. We have less confidence in the delineation of small regions, but the prominent areas in South America and near the Himalayas match that of Toracinta and Zipser (2000). There is a hint of the central US area in Toracinta and Zipser, but the northern end of the analysis cuts off at $35^{\circ} \mathrm{N}$, near the southern extent of the maximum seen in Fig. 8.5. In passing, we note that possible problems exist in the reanalysis depiction. In particular, there is a two-point wide line in the reanalysis just east of the Andes that appears to result from the response to the depiction of the Andes in spectral space. The regions in northeastern Mexico and near the Arabian Peninsula are also likely overestimated, given the lightning distribution derived from the Tropical Rainfall Measuring Mission - Lightning Imaging Sensor observations. Brooks et al. (2003b) noted problems with the representation of the capping inversion frequently seen in observations that suppresses the formation of convection in the atmosphere.

The reanalysis estimate of the distribution of significant tornado environments is dominated by the central USA, with lesser maxima over South America, and southeast China. As mentioned earlier, the discrimination of tornadic conditions is poorer than the discrimination of severe conditions. It may be overly tuned to the conditions associated with outbreaks in the USA. It is possible that conditions that are relatively rarely observed in the USA may be sufficient for tornadoes, but absent in the discrimination. Given that the reanalysis would be expected to be best in depicting large-scale synoptic conditions, locally concentrated regions may be missed, as well. 


\section{HISTORICAL CHANGES IN ENVIRONMENTS}

Studies of the historical distribution of severe thunderstorms and tornadoes and possible changes are necessarily limited by the data quality. However, efforts to date have not detected statistically significant changes. Concannon et al. (2000) found large variability between different periods in the record of strong and violent tornadoes in the USA. In their analysis of tornadoes in Germany, Bissolli et al. (2006) reported no shift of the seasonal cycle detectable for the period 1980-2003 compared to 1950-2003 and also no shift of the intensity distribution.

Severe thunderstorms and tornadoes are products of the juxtaposition of relatively rare conditions on sub-synoptic scales. Attempting to estimate likely changes with their occurrence associated with climate change scenarios is difficult, at best (cf. IPCC, 2001). Considering the mean annual conditions in mid-latitudes, we might expect CAPE to increase as a result of increasing surface temperature and boundarylayer moisture in a warming world. Gaffen and Ross (1999) presented observational evidence for an increase in boundary-layer moisture in the southern US in summer. To first order, deep tropospheric wind shear might be expected to decrease from thermal wind considerations if the equator-to-pole temperature gradient decreases. The question of the balance between those changes would determine if more environments were found in the higher probability space shown in Fig. 8.4.

The mean picture is of limited value, however. Given the relationship of large-scale orographic features to the location of the maxima in favorable environments, the locations of future events may be constrained by those large-scale features. More importantly, we are interested in the combination of conditions on a day-to-day basis. It is possible that days with the greatest increase in CAPE could be when the deep shear is small, so that the change in severe threat might be small. Brooks et al. (2006) have shown that CAPE and deep shear tend to be out-of-phase in their annual cycle. 

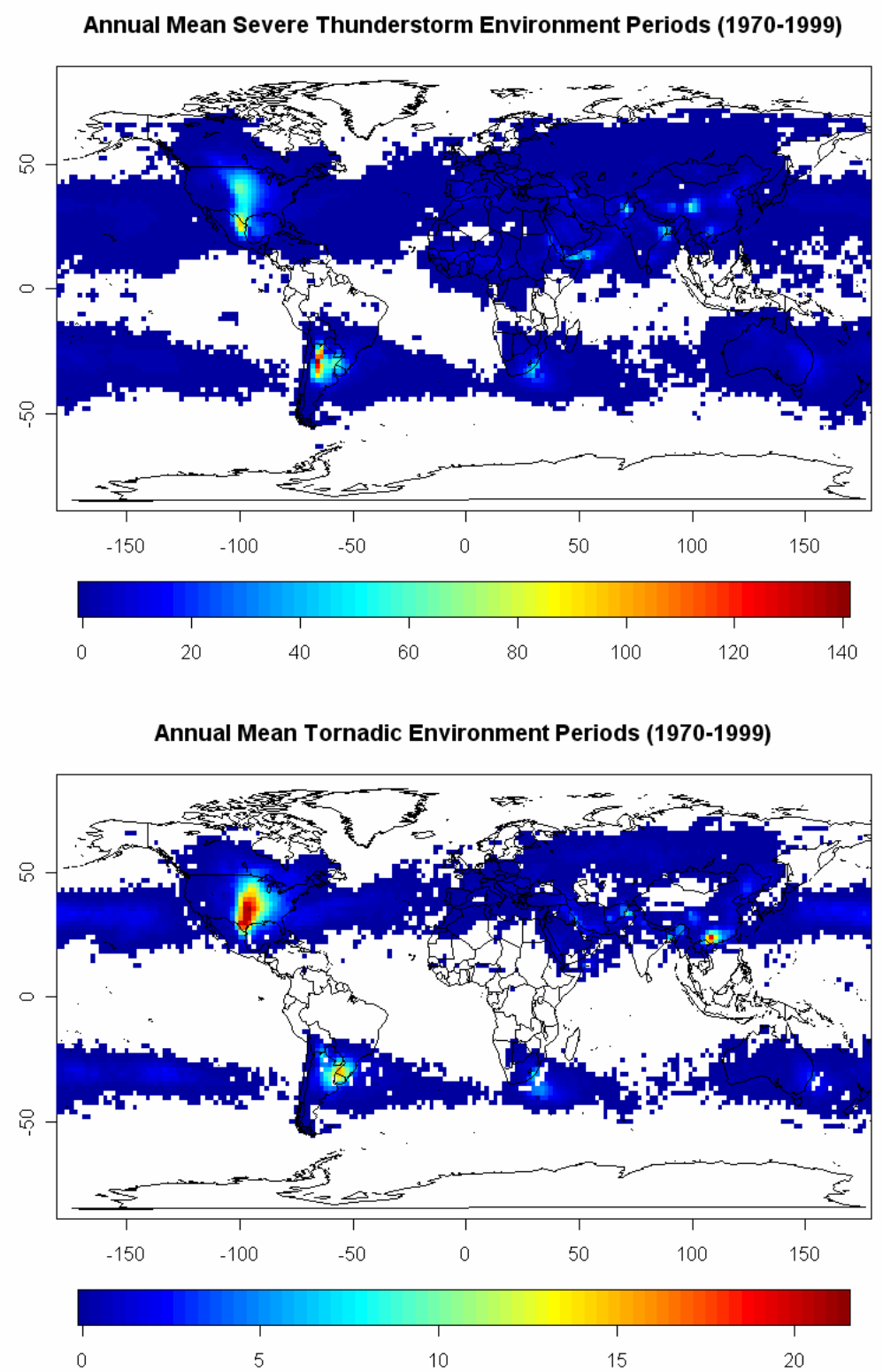

Figure 8.5. Six-hourly periods per year with environments supportive of significant severe thunderstorms (top) and significant tornadoes (bottom) based on NCAR/NCEP reanalysis data from 1970-1999. [Updated from Brooks et al. (2003b)]. 


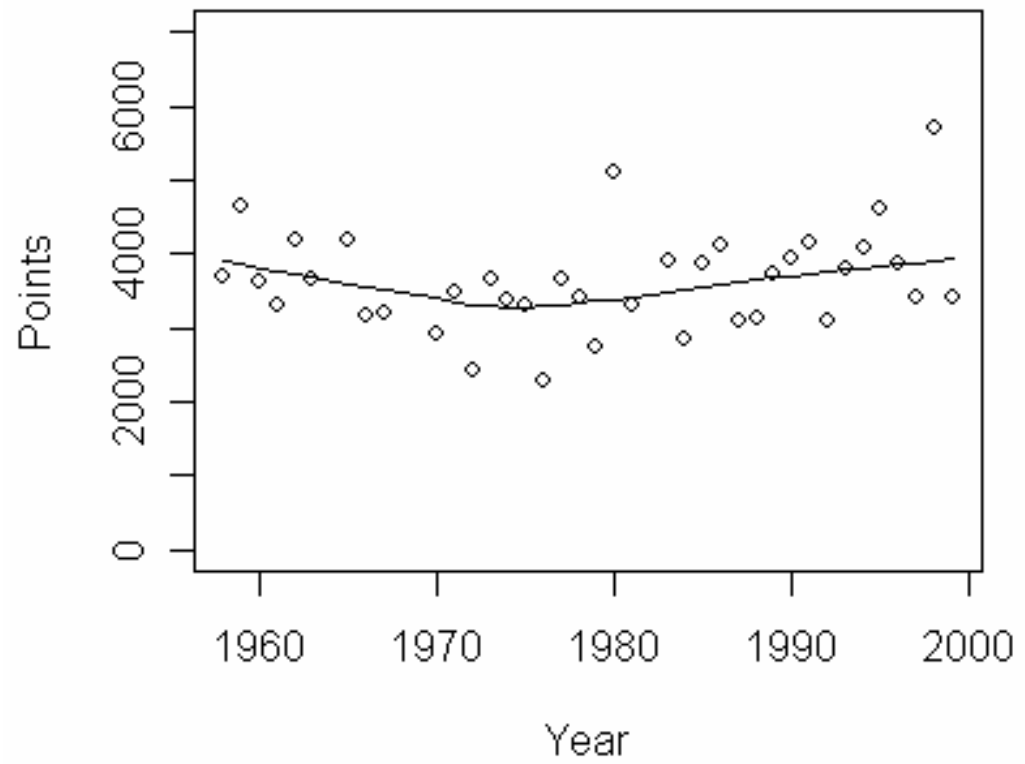

Figure 8.6. Six-hourly periods per year with environments supportive of significant severe thunderstorms in USA east of Rocky Mountains. Line is local regression fit to series.

Again, the reanalysis data can provide insight into historical behavior (Brooks 2006). The annual total of points that are identified as favorable for severe thunderstorms in the US, east of the Rocky Mountains, shows a minimum in the early 1970s (Fig. 8.6). From the time of the minimum to 1999, the annual total increased by about $0.8 \%$ per year. There is a superficial similarity to the US annual temperature record, but it is not statistically significant. Unfortunately, the reanalysis does not extend back in the same format before 1958. Thus, we cannot be sure of the long-term relationship between surface temperature and favorable storm environments in the US.

We can compare the number of environments to reports of $7 \mathrm{~cm}$ diameter or larger hail in the US over a comparable period. As mentioned earlier, there has been a large increase in the number of hail reports in the US, but the increase in the largest hail has not been so great, although it is still large (Fig. 8.7). There is an inflection in 
the record at the same time (1973) as the environmental estimate. Prior to that, the hail reports are essentially flat, while the environments decreased by about $1 \%$ per year. Since then, the number of reports has increased by $6 \%$ per year. If we take the estimate of environments as a baseline, the change in environments is $13 \%$ of the change in reports.

Other regions show different trends in environments. In particular, a region encompassing the South American maximum shows a decrease of almost $40 \%$ over the period of the reanalysis (Fig. 8.8). Caution has to be applied in interpreting this figure, the large data-sparse region associated with the Pacific and the relatively small data-filled region of South America. It is possible that the changes are due to analysis or data issues, particularly in the early part of the reanalysis record.

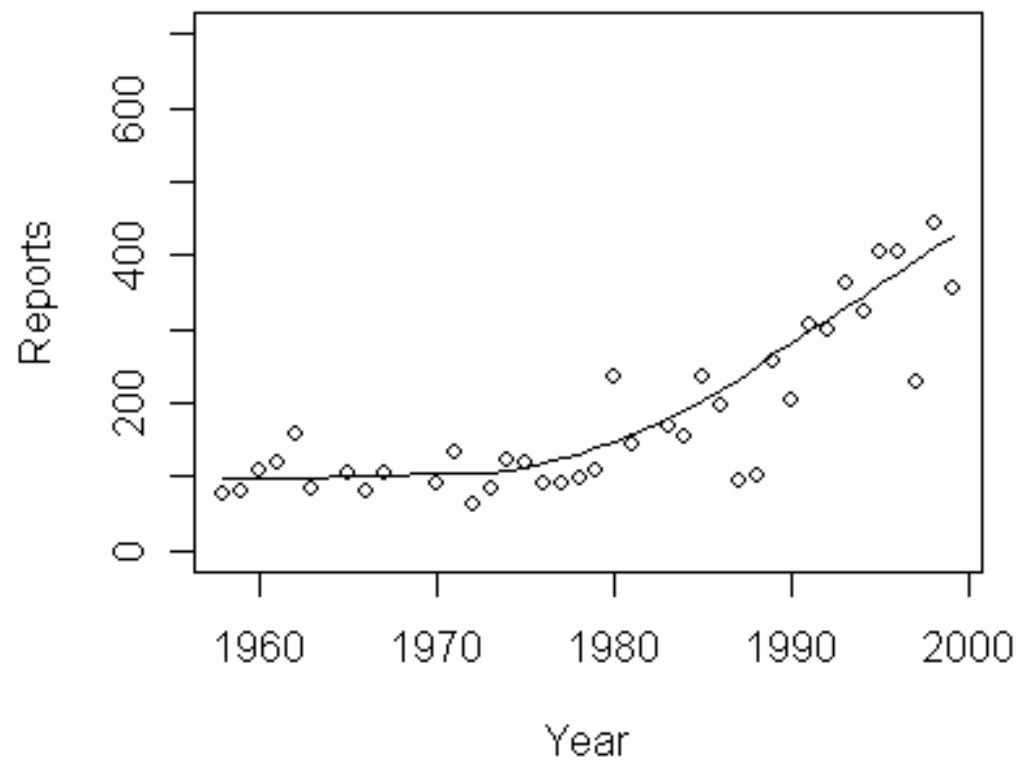

Figure 8.7. Number of reports of hail $7 \mathrm{~cm}$ or larger in diameter in USA per year. Line is local regression fit to series. 


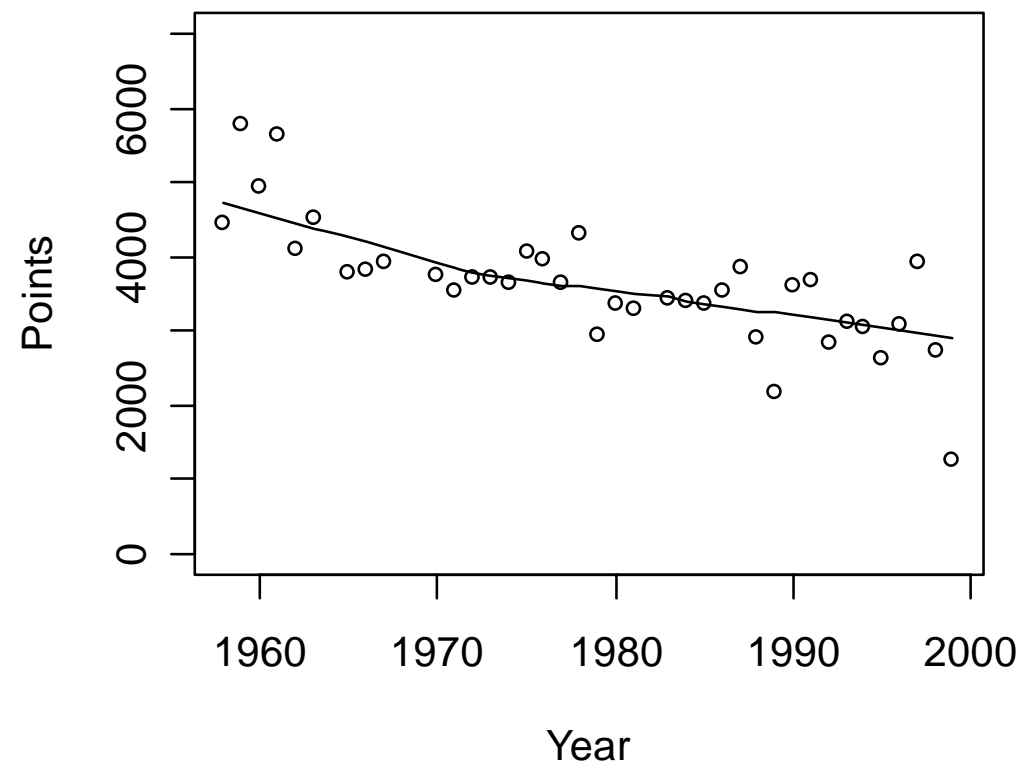

Figure 8.8. Same as Figure 8.6, except for region of equal size encompassing local maximum in severe thunderstorm count in South America shown in Figure 8.4.

\section{CONCLUSIONS AND FUTURE NEEDS}

Many of the questions raised here could be addressed by better collection of reports. At the very least, that would provide a baseline of occurrence of events. At a deeper level, large data sets of events would be useful for the development of improved relationships between environments and events. Those could then be used to refine the reanalysis estimates of favorable environments. To that end, the development of a European Severe Weather Database for the entire continent is an important step. Significant tornadoes do occur in Europe (e.g. Wegener, 1917; Fulks, 1967, 1969; Laun, 1969; Dotzek, 2001, 2003), but the reanalysis appears to underestimate them. This underestimate could occur for a variety of reasons, including the failure to identify the environments in which they occur, poor representation of important processes like orographic forcing in the reanalysis, or differences in the efficiency of the atmosphere to take an environmental condition and produce a storm. 
In order to look at climate change effects, though, analysis of climate model simulations will have to be carried out. The challenge is that there are important differences compared to the reanalysis problem. The reanalysis has observed events to tie itself to reality. A priori, the ability of the models to represent the future distribution is unknown, and relies strongly on successful verification of present-day simulations. In the model world, this verification can be done by simulating the climate of recent decades, and relating derived quantities (analogous to the reanalysis approach) to observed severe convective storm events. This further substantiates the need for reliable, homogeneous, long-term severe weather report databases. Only after such verification, analysis of the distribution of environments in (regional) climate model runs for future scenarios can become feasible, even without having particular severe weather events to which to tie them. It is likely that the analysis will require the development of relationships that are unique to the models. If they can be developed, changes in the distributions in climate change scenarios could be evaluated. The models also have the advantage of producing very large samples of environments, both in space and time, from which the distributions can be studied.

Severe thunderstorms and tornadoes will continue to be a threat. Increases in population and wealth mean that larger losses are possible (Brooks and Doswell 2001a), even without changes in the meteorological events. Thus, awareness of the threats is important. If, however, changes in the distribution of those threats could be identified, additional preparation for them could be carried out.

\section{ACKNOWLEDGMENTS}

HB has been supported over the years by a grant from the NOAA Office of Global Programs and by the NCAR Weather and Climate Assessment Initiative. ND has been supported by a DLR Forschungssemester grant as a visiting scientist to NOAA-National Severe Storms Laboratory.

\section{REFERENCES}


Beebe, R. G. 1955. Types of airmasses in which tornadoes occur. Bull. Am. Meteorol. Soc. 36: 349-350.

Beebe, R. G. 1958. Tornado proximity soundings. Bull. Am. Meteorol. Soc. 39: 195-201.

Bissolli, P., J. Grieser, N. Dotzek, and M. Welsch. 2006. Tornadoes in Germany 1950-2003 and their relation to particular weather conditions. Global and Planetary Change, in press.

Brooks, H. E. 2004. Tornado warning performance in the past and future: A perspective from signal detection theory. Bull. Amer. Meteorol. Soc. 85: 837-843.

Brooks, H. E. 2006. A global view of severe thunderstorms: Estimating the current distribution and possible future changes. Preprints, Syposium on the Challenges of Severe Convective Storms, Atlanta, Amer. Meteorol. Soc., Conference CD. [Available at http://www.nssl.noaa.gov/users/brooks/public_html/papers/AMS2K6. pdf]

Brooks, H. E., A. R. Anderson, K. Riemann, I. Ebbers, and H. Flachs. 2006. Climatological aspects of convective parameters from the NCAR/NCEP reanalysis. Atmos. Res. in press.

Brooks, H. E., and J. P. Craven. 2002. A database of proximity soundings for significant severe thunderstorms. 1957-1993. Preprints, 21st Conference on Severe Local Storms, San Antonio, Amer. Meteorol. Soc. 639-642.

Brooks, H. E., and C. A. Doswell III. 2001a. Normalized damage from major tornadoes in the United States: 1890-1999. Wea. Forecasting 16: 168-176.

Brooks, H. E., and C. A. Doswell III. 2001b. Some aspects of the international climatology of tornadoes by damage classification. Atmos. Res. 56: 191-201.

Brooks, H. E., Doswell III, C. A., and J. Cooper. 1994. On the environments of tornadic and nontornadic mesocyclones. Wea. Forecasting 9: 606-618.

Brooks, H. E., C. A. Doswell III, and M. P. Kay. 2003a. Climatological estimates of local daily tornado probability. Wea. Forecasting 18: 626-640. 
Brooks, H. E., J. W. Lee, and J. P. Craven. 2003b. The spatial distribution of severe thunderstorm and tornado environments from global reanalysis data. Atmos. Res., 67-68: 73-94.

Brown, B. G., and Murphy, A. H.. 1996. Verification of aircraft icing forecasts: The use of standard measures and meteorological covariates. Preprints, 13th Conf. Probability and Statistics in the Atmospheric Sciences, San Francisco, California, USA, Amer. Meteorol. Soc. 251-252.

Concannon, P. R., H. E. Brooks, and C. A. Doswell III. 2000. Climatological risk of strong and violent tornadoes in the United States. Preprints, 2nd Symposium on Environmental Applications, Long Beach, California, Amer. Meteorol. Soc 212-219.

Conradsen, K., L.B. Nielsen, and L.P. Prahm. 1984. Review of Weibull statistics for estimation of wind speed distributions. J. Cli. Appl. Meteor. 23: 1173-1183.

Craven, J. P., and H. E. Brooks. 2004. Baseline climatology of sounding derived parameters associated with deep, moist convection. Nat. Wea. Digest, 28: 13-24.

Doswell, C. A. III, H. E. Brooks, and R. A. Maddox, 1996. Flashflood forecasting: An ingredients-based methodology. Wea. Forecasting, 11: 360-381.

Doswell, C. A. III, ed.. 2001. Severe Convective Storms, Meteorol. Monogr. No. 50. Boston: Amer. Meteorol. Soc., 561 pp.

Doswell, C. A. III, H. E. Brooks, and M. P. Kay. 2005. Climatological estimates of daily local nontornadic severe thunderstorm probability for the United States. Wea. Forecasting. 20: 577-595.

Dotzek, N. 2001. Tornadoes in Germany. Atmos. Res. 56: 233-251.

Dotzek, N. 2003. An updated estimate of tornado occurrence in Europe. Atmos. Res. 67-68: 153-161.

Dotzek, N., J. Grieser, and H. E. Brooks. 2003. Statistical modeling of tornado intensity distributions. Atmos. Res. 67-68: 163-187.

Dotzek, N., M. V. Kurgansky, J. Grieser, B. Feuerstein, and P. Névir. 2005. Observational evidence for exponential tornado intensity distributions over specific kinetic energy. Geophys. Res. Lett. 32: L24813, doi:10.1029/2005GL024583. 
Feuerstein, B., N. Dotzek, and J. Grieser. 2005. Assessing a tornado climatology from global tornado intensity distributions. J. Climate 18: 585-596.

Fujita, T. T. 1971. Proposed characterization of tornadoes and hurricanes by area and intensity. SMRP Res. Paper 97, Univ. of Chicago, 42 pp.

Fulks, H. W. 1967. Thunderstorms and related severe weather in Europe. European Theater Weather Orientation (ETWO), U.S. Air Force Europe, July 1967.

Fulks, H. W. 1969: A synoptic review of the Pforzheim tornado of 10 July 1968. Tech. Bull. 2nd Wea. Wing, Air Weather Service, U.S. Air Force, April 1969, 26-43.

Gaffen, D. J., and R J. Ross. 1999: Climatology and trends of U.S. surface humidity and temperature. J. Climate 12: 811-828.

Intergovernmental Panel on Climate Change. 2001. Climate Change 2001 - The Scientific Basis. Cambridge University Press, Cambridge, $881 \mathrm{pp}$.

Intergovernmental Panel on Climate Change. 2002. Workshop Report, IPCC Workshop on Changes in Extreme Weather and Climate Events, Beijing, China, 107 pp.

Kelly, D.L., J.T. Schaefer, R.P. McNulty, C. A. Doswell, and R.F. Abbey, Jr. 1978. An augmented tornado climatology. Mon. Wea. Rev. 106: $1172-1183$.

Kurgansky, M. V. 2000. The statistical distribution of intense moistconvective, spiral vortices in the atmosphere. Doklady Earth Sci., 371: 408-410. [Available from essl.org/pdf/Kurgansky2000.pdf]

Laun, W. 1969. An investigation of recent tornadoes over France and Germany. Tech. Bull. 2nd Wea. Wing, Air Weather Service, U. S. Air Force, April 1969, 3-25.

Lee, J. W. 2002. Tornado proximity soundings from the NCEP/NCAR reanalysis data. M.S. Thesis, University of Oklahoma, $61 \mathrm{pp}$.

Levizzani V., and M. Setvák. 1996. Multispectral, high-resolution satellite observations of plumes on top of convective storms. $J$. Atmos.Sci. 53: 361-369.

Maddox, R. A., K. W. Howard, and C. L. Dempsey. 1997. Intense convective storms with little or no lightning over central Arizona. A case of inadvertent weather modification? J. Appl. Meteorol. 36: 302314. 
Rasmussen, E. N. and D. O. Blanchard. 1998. A baseline climatology of sounding-derived supercell and tornado forecast parameters. Wea. Forecasting 13: 1148-1164.

Toracinta, E. R. and E. J. Zipser. 2000. Lightning and SSM/I-icescattering mesoscale convective systems in the global tropics. J. Appl Meteorol. 40: 983-1002.

Trapp, R. J., D. M. Wheatley, N. T. Atkins, R. W. Przybylinski, and R. Wolf. 2006. Buyer beware: Some words of caution on the use of severe wind reports in postevent assessment and research. Wea. Forecasting 21: 408-415.

Verbout, S. M., H. E. Brooks, L. M. Leslie, and D. M. Schultz. 2006. Evolution of the US tornado database: 1954-2003. Wea. Forecasting 21: 86-93.

Wegener, A. 1917. Wind- und Wasserhosen in Europa (Tornadoes in Europe). Die Wissenschaft, Bd.60, Verlag Friedrich Vieweg und Sohn, Braunschweig, 301 pp. [In German, available at essl.org]. 